\title{
Use of Social Media in Health
}

\section{Care-Opportunities, Challenges, and Ethical Considerations}

\section{A Position Statement of the American Academy of Neurology}

Katharina M. Busl, MD, MS, Michael A. Rubin, MD, MA, Benjamin D. Tolchin, MD, MS, Dan Larriviere, MD, JD, Leon Epstein, MD, Matthew Kirschen, MD, PhD, and Lynne P. Taylor, MD, on behalf of the Ethics, Law, and Humanities Committee, a joint committee of the American Academy of Neurology, American Neurological Association, and Child Neurology Society

Neurology ${ }^{\circledR} 2021 ; 97: 585-594$. doi:10.1212/WNL.0000000000012557

The American Academy of Neurology (AAN) Code of Professional Conduct (CPC) $)^{1}$ formalizes the standards of professional behavior for AAN members. The CPC provides the ethical principles and professional standards that neurologists and other neuroscience professionals should or must observe in their clinical and scientific activities. While ethical principles do not change with time, developments in technology and social structure may lead to a change in how these principles are applied. One such technological development is social media-a class of communication tools that has rapidly grown in number and popularity in recent years. The AAN developed this position statement to review in-depth how social media use has transformed clinical practice, with a particular focus on neurologic practice, and, by exploring the relevant principles in the $\mathrm{CPC},{ }^{1}$ to provide an ethical framework for neurology professionals and trainees to consider when engaging in social media. This statement complements the CPC; it is not a replacement for the AAN Web site's Code of Conduct, Privacy Policy, or Terms of Service.

The use of social media has become nearly ubiquitous. Social media applications are widely available, free or of low cost, and not limited by geographic or temporal boundaries. Nearly $70 \%$ of adults in the United States use at least one social media platform. ${ }^{2}$ The most frequent consumers of social media are those between 18 and 29 years of age, but the number of older consumers has continued to increase over the years, especially between 30- and 49-year-olds. While use of social media is equally common across divisions of race and sex, it remains most frequent among those with some form of college education. ${ }^{3}$ More than half of adults use social media in the United States to obtain health care information, and this number is expected to continue to grow. ${ }^{4}$ Among physicians, $90 \%$ use at least one social media modality in their personal lives, and $67 \%$ use one professionally. ${ }^{5}$ Among the many social media applications, health care systems most commonly use Facebook and YouTube for marketing; Twitter, LinkedIn, Instagram, and blogs play an important role in professional communities. ${ }^{2}$

Social media has transformed personal and professional lives, raising important ethical questions for health care and clinicians. We review the medico-ethical challenges that the advent of social media presents, with special attention to issues facing neurologists. Existing ethical principles and norms of professional communication can and should serve as the framework for guiding the professional use of social media by neurologists and other clinicians.
Correspondence Dr. Busl katharina.busl@ neurology.ufl.edu 


\section{Glossary}

AMA = American Medical Association; COVID-19 = coronavirus disease 2019; HIPAA = Health Insurance Portability and Privacy Act.

\section{How Social Media Has Enriched the Medical Profession}

\section{Information Exchange, Distribution, and Networking}

Social media enables professional connection and networking. Through social media, trainees engage with national societies earlier in their career, leading to service on a national committee and relationships with leaders in the field. Joining Twitter accelerates professional development and uncovers opportunities that otherwise would have been difficult to access. ${ }^{3}$ Participation in social media is helpful for amplifying the impact of one's work and providing new opportunities for academic scholarship. ${ }^{6}$ Social media provides access to unparalleled professional development opportunities. ${ }^{2}$ Altmetrics is quickly emerging as a novel metric for quantifying the dissemination, discussion, and impact of online contributions, and it might eventually be used as a metric in the academic promotion process. ${ }^{7}$ Using social media purposefully can (1) amplify brand-building efforts such as speaking engagements, medical journal articles, or news media engagements; (2) advance one's professional passions; (3) teach patients and the general public; (4) attract patients; and (5) publicize research. ${ }^{8}$ Networking not only leads to peer-topeer referrals - Twitter users also report that patients have self-referred after following specific neurologists' tweets. ${ }^{9}$

All of these opportunities require careful forethought and crafting. Simply signing up and using a given platform will not lead to success. A first step for an individual or an organization is to establish clear goals for use of social media - setting the direction for a social media plan, defining priorities, and ensuring conveyance of intended messages. ${ }^{2}$ For clinicians and health care organizations, improving the health of patients and the broader community should be the foremost goals in any social media plan, taking precedence over personal and economic goals, as required by the ethical principles of beneficence and justice.

\section{Education and Research}

Use of Internet-based platforms and social media has changed the landscape of education dramatically in recent years. ${ }^{10}$ Free Open Access Medical Education and Free Open Access Radiology Education describe new methods of medical educators aiming to provide trainees with access to free online educational resources. ${ }^{11}$ Within neurology education specifically, several existing programs-such as problem-based learning and case discussions for neurologic intensive care unit nurses ${ }^{12}$ and rapid dissemination of information in the field of neuropathology ${ }^{13}$ - may have the potential to improve primary and continued medical education. On the other hand, use of social media in graduate medical education revealed mixed results regarding effect on education, recruitment, and professionalism. ${ }^{14}$ Similarly, social media-based interventions have thus far had poor results in the dissemination and implementation of clinical practice guidelines: social mediabased dissemination methods did not confer additional benefit over print-, email-, or Internet-based methods in increasing awareness and changing intent in physicians or patients. ${ }^{15}$

Utilization of social media for research is another growing trend. Many investigators post their ideas and trials on professional platforms, eliciting more immediate and widespread discussion and communication than was previously achieved through traditional media. Furthermore, announcing clinical studies via social media has successfully facilitated community consultation and public disclosure activities. ${ }^{16}$ Recruitment of potential study subjects using social media is still a relatively new phenomenon, and it might bring advantages, but also dilemmas. ${ }^{17}$ Social media has a diverse group of users and may be one avenue for researchers to begin to locate and recruit a more diverse sample, ${ }^{18}$ but it might be complicated by the number of popular social media platforms available to the public and the limitations posed by selection bias. Another recently reported application of social media was a move for drug repositioning to accelerate drug development in Parkinson disease where, without social media, such development would likely be delayed. ${ }^{19}$

\section{Patient Education, Counseling, and Treatment}

The role of physicians includes not just treatment of patients in the office or hospital, but also education to advance patients' and families' overall knowledge and understanding of health and health literacy, ${ }^{8}$ a task that has taken on new dimensions with universal access to and distribution of information online. This role accords with the principle of beneficence, which requires clinicians to act to promote their patients' health, and the principle of justice, which requires clinicians to consider the effect of their actions on other members of their community beyond their current patients. The wide availability of and easy access to information on social media and the Internet adds to clinicians' responsibility to educate the public and to protect our patients from misinformation: if we, as clinicians, do not provide accurate information, the public may be exposed to misinformation that is widely shared on social media. Verification of information presented online is difficult, and it has been shown that the rate and speed of false information diffusion through online media is nearly 10 -fold greater than the rate and speed of true information diffusion. ${ }^{20}$ These findings hold true also in 
content specific to neurology: an analysis of Korean videos on Parkinson disease revealed that videos with reliable content were less popular than videos with misleading content. $^{21}$ Furthermore, content on media available for patients and families may not always present information in a balanced manner. A study searching Facebook and Twitter for public accounts on epilepsy found that provision of information and correction of common misconception in epilepsy was the most common theme, and surgical options were only mentioned in $1 \%$ of posts. ${ }^{22}$ Another illustration of the power and potential value of social media is presented in a qualitative analysis of the a Twitter hashtag referencing patients' negative experiences with their doctors (\#DoctorsAreDickheads). ${ }^{23}$ Among the 40,000 posts associated with this viral hashtag, the most commonly mentioned conditions included chronic pain and mental health, both themes very relevant to the field of neurology. Specific issues identified included physicians' disbelief in patients' experiences and power inequity between patients and clinicians. This analysis highlights how social media shapes the public's view of medical professionals' behavior, and also offers an opportunity to learn about patients' needs and strategies to improve in communication with patients.

How can social media enhance treatment? For physicians, social media can be one way to stay abreast of the latest research findings in their field and a source of medical education and discussion. Examples include "tweetorials" and case studies or pictures used as diagnostic tools to illustrate features such as ptosis or facial palsy. ${ }^{24}$

When faced with her son's acute illness and acute flaccid myelitis, one neurologist found that, despite being a medical professional specializing in the diagnosis and treatment of the disorder that was afflicting her child, she still experienced important gaps between his inpatient and outpatient care. ${ }^{25}$ Through a Facebook group, she gained information on recommended rehabilitation experts, electrical stimulation devices and settings, and templates for letters to insurers. ${ }^{25}$ Furthermore, social media opened pathways through which knowledge could flow back to medical professionals. In a study evaluating a Facebook support group for liver transplant patients, integration of social media into clinical practice empowered surgeons to synthesize a patient support community, augmenting patient engagement and satisfaction. $^{26}$ In a systematic review on the effect of social media on chronic disease, $48 \%$ of studies indicated some benefit, $45 \%$ were neutral or undefined, and $7 \%$ suggested harm. Among studies that showed benefit, $85 \%$ used either Facebook or blogs, and $40 \%$ were based within the domain of support. ${ }^{27}$ In the face of changing online landscapes, these data are likely also subject to change, but 2 main messages remain. First, it is evident that in the right setting, employment of social media might greatly enhance individual patient or caregiver journeys. Second, given these findings, an important question for clinicians is how much-if anyinformation regarding social media support groups that could potentially enhance traditional approach to care are we obliged to share?

In analyses of health care-related hashtags on social media, patients and patient advocates made the majority of posts, but physician use is steadily growing. ${ }^{23,28}$ The World Medical Association's Declaration of Geneva pledges health care professionals to "share medical knowledge for the benefit of the patient and the advancement of healthcare." 29 Social media may be an attractive mechanism for meeting this ethical and professional obligation, especially during the coronavirus disease 2019 (COVID-19) pandemic and other public health emergencies when regular access to in-person information and treatment are limited. ${ }^{30}$ In such situations, innovative approaches are necessary to ensure continuity of $\operatorname{care}^{31}$ and broad access to updates as well as forums to interactively ask questions. $^{32}$

Recommending social media resources to patients and families may also carry some risk of harm. As outlined above, diffusion of false information is a common problem. For some social media users, the perceived need to be online may result in compulsive use of social networking sites, which-in extreme cases-may result in symptoms and consequences traditionally associated with substance-related addictions, including fear of missing out (FOMO) and smartphone addiction as well as nomophobia (no mobile phone phobia). ${ }^{33}$

\section{Participation in Social Media and Associated Challenges}

The traditional ethical principles of beneficence and justice, combined with our duty as physicians to inform, not only permits, but may encourage use of social media for networking, education, research, and patient care. However, these principles have to be weighed against the principles of primum non nocere (above all, do no harm), right of privacy, and confidentiality.

\section{How to Conduct Oneself When Using Social Media}

When considering how to conduct oneself, the existing norms of professional communication, rooted in the established principles of medical ethics, serve as the starting point. ${ }^{34}$ Contemporary medical ethics, including the ethics of professional social media use, can be understood and framed by a system known as principlism: patient autonomy, beneficence, nonmaleficence, and justice. ${ }^{35}$ The principle of respect for autonomy requires clinicians to respect patients' inherent right of self-determination, to promote patients' control over their own medical care, and specifically to allow patients to make informed and uncoerced decisions to consent to or refuse medical interventions. The principle of beneficence requires clinicians to promote their patients' welfare and health. The related principle of nonmaleficence requires 
Table 1 Application of Principlism (Examples) and Related Ethical Principles

\begin{tabular}{ll}
\hline $\begin{array}{l}\text { To be cognizant of and maintain standards of } \\
\text { patient privacy and confidentiality }\end{array}$ & $\begin{array}{l}\text { Nonmaleficence and } \\
\text { autonomy }\end{array}$ \\
\hline $\begin{array}{l}\text { To follow ethics guidance regarding } \\
\text { confidentiality, privacy, and informed consent }\end{array}$ & $\begin{array}{l}\text { Nonmaleficence and } \\
\text { autonomy }\end{array}$ \\
\hline $\begin{array}{l}\text { To use privacy settings to safeguard personal } \\
\text { information and content to the extent possible }\end{array}$ & Nonmaleficence \\
$\begin{array}{l}\text { with the understanding that privacy settings } \\
\text { are not infallible and that information once } \\
\text { posted on the Internet is difficult or impossible } \\
\text { to erase }\end{array}$ & \\
\hline $\begin{array}{l}\text { To maintain appropriate boundaries of the } \\
\text { patient-physician relationship }\end{array}$ & $\begin{array}{l}\text { Beneficence and } \\
\text { nonmaleficence }\end{array}$ \\
\hline $\begin{array}{l}\text { To consider separation of personal and } \\
\text { professional content online }\end{array}$ & \begin{tabular}{l} 
Nonmaleficence \\
\hline $\begin{array}{l}\text { To bring unprofessional content to attention } \\
\text { To recognize that actions online and content } \\
\text { posted may have consequences }\end{array}$
\end{tabular} \\
$\begin{array}{l}\text { To avoid use of social media that distracts from } \\
\text { or otherwise impairs clinical care }\end{array}$ & $\begin{array}{l}\text { Beneficence and } \\
\text { nonmaleficence }\end{array}$ \\
\hline
\end{tabular}

clinicians to avoid and avert harm to their patients. The principle of justice requires that clinicians take into account the effect of their actions on society, and attempt to ensure that the benefits and burdens of health care are distributed fairly. In our view and in the view of many medical ethicists, the principle of autonomy also requires clinicians to communicate honestly, out of respect for their patients as autonomous ends in themselves. ${ }^{36,37}$

Each of these principles applies to professional communication on social media, just as they do to professional conduct and communication in face-to-face interactions. For example, the principles of nonmaleficence and autonomy prohibit the publication of confidential clinical information or images without informed consent. The principles of beneficence and justice support the dissemination of accurate health information, such as the results of clinical studies, for the purpose of public education. The principles of both nonmaleficence and beneficence also demand that sharing or posting of false information be avoided, requiring proper fact-checking and vetting of information prior to dissemination-action items that require awareness and digital literacy. ${ }^{38}$ Another challenge with digital media, when compared to traditional media, is that they extend beyond spatial and temporal constraints. As a result, norms of communication widely accepted in one part of the world might not be standard in another, where social media outlets still will reach.

With regard to regulatory bodies, it is important to recognize that improper use of social media can adversely affect the clinician. Credentialing and licensing authorities as well as boards have the authority to impose restrictions or limit licenses. ${ }^{39}$ Furthermore, use of social media can invoke complex legal issues, and awareness that most social media content will be considered discoverable is important. ${ }^{39}$

Many societies and professional organizations have issued policies on the use of social media. The American Medical Association (AMA) issued a policy on the use of social media in $2010^{40,41}$ and the American College of Physicians and the Federation of State Medical Boards together issued guidelines on online medical professionalism in $2013 .{ }^{42}$

Examples of the application of principlism are shown in Table 1. The case example shows a possible scenario when engaging social media and analyzes the ethical principles involved.

These norms for professional communication, applied in the setting of social media, raise several additional important questions. We can generalize the core ethical principles to circumstances not covered by the norms published by professional organizations.

\section{What Is the Clinician's Responsibility for Ensuring That Privacy Is Maintained on Social Media?}

Social media is qualitatively different from (and less secure than) software platforms built specifically for secure clinical use in compliance with the Health Insurance Portability and Privacy Act (HIPAA). Privacy concerns may limit the use of social media in the health care system. ${ }^{43}$ Proprietary HIPAAcompliant health care portals operated by hospitals and other health care institutions may attempt to use some selected features of social media applications with enhanced privacy and security. However, data breaches on social media are common, often unforeseen, and outside the control of both users and social media companies. In some documented cases, social media companies have themselves participated in or allowed data breaches. ${ }^{44,45}$ Private thoughts, writings, or photographs can rapidly become public through social media ${ }^{46}$ regardless of their users' intentions. There is a false sense of privacy and anonymity inherent to online interactions, which may foster disinhibition and sharing of private information that would not ordinarily be publicized. ${ }^{47} \mathrm{~A}$ review of physician postings to Twitter in 2013 revealed that $1.9 \%$ of the tweets were labelled as "unprofessional." Among these were posts that included information that could violate patient privacy. ${ }^{48}$ In a more recent analysis of Twitter data, patient names were mentioned in $2 \%$ of health care-related tweets by clinicians, and other elements of the tweets not traditionally defined as identifiers were judged identifiable by families or friends for nearly one third of the tweets, and even more when tweets pertained to patients who were still alive. ${ }^{49}$ These potential privacy violations are concerning because the reach of social media posts is potentially unlimited in geography and time, and because posts are often effectively irreversible once disseminated. Another consideration for maintenance of privacy is to use the blind carbon copy (BCC) function in email or email-like messaging when addressing a group, so that individual recipients cannot see each other's contact information. 
Table 2 Code of Conduct for Use of the American Academy of Neurology (AAN) Web Site

Courtesy: Do not attack others. Comments are meant to stimulate conversation, not to create contention. Let others have their say, just as you may.

Do not post commercial messages: The AAN's web site is to be used for noncommercial purposes only. Contact people directly with products and services that you believe would help them.

Privacy laws: Remember to comply with HIPAA and other privacy laws. Accordingly, when talking about patients or submitting any image or video regarding a patient, be sure to follow HIPAA and disclose only deidentified health information.

Use caution: Information and comments posted on the web site are available for all to see, and comments are subject to libel laws. Do not post any defamatory, abusive, profane, threatening, offensive, or illegal content.

Antitrust: The AAN complies with all antitrust laws in accordance with the AAN Antitrust Policy. The AAN reminds all users to guard against activity that could be construed as a violation of the Antitrust Policy, including posting any material that:

- References specific fees charged or paid for professional services

- Discusses prices, discounts, terms, or conditions of sale with regard to medical suppliers or other vendors, terms and conditions of provider agreements relating to reimbursement levels, bonus payments, and other price- or cost-related items

- Addresses salaries or terms of employment

- Attempts to allocate patient markets or encourage collective or coercive activity with regard to third-party payers, hospitals, other health care providers, or suppliers

- Includes information that might otherwise be construed to impose a restraint on trade and inhibit free and fair competition

Intellectual property: Respect others' intellectual property rights. Do not post any copyrighted material, trademarks, or other proprietary information without the permission of its owner.

Abbreviation: HIPAA = Health Insurance Portability and Privacy Act.

The Code of Conduct for the use of the AAN web site is available in the footer of each webpage on AAN.com. ${ }^{50}$

\section{Does the Potential Risk of a Data Breach Require Clinicians to Avoid Posting or Communicating on Social Media, or Are There Constraints and Precautions Under Which Clinicians Can Use Social Media While Adhering to the Principles of Professional Ethics?}

Given clinicians' inability to guarantee the security and privacy of data posted on social media, the AMA's recommendation is that clinicians refrain from posting identifiable patient information on social media without the written informed consent of the patient or legal surrogate. ${ }^{40,41}$ This guidance accords with the fundamental ethical principles of autonomy and nonmaleficence, which require clinicians to promote patient control over personal health information and to act to minimize risk of harm to patients and to their interests. Given the possibility of unauthorized use of posted data by social media companies or third parties, identifiable patient information should not be posted to social media in either public or private forums without explicit written informed consent. This is of specific importance when considering forums' "private" or semi-private spaces, including for example Synapse. Given the possibility of unauthorized use of posted data by third parties, virtually no online forum should be considered fully private. The AMA also recommends that information posted to social media for educational purposes follow ethics guidance regarding confidentiality, privacy, and informed consent. As a heuristic, posting on social media (even in supposedly private forums) should only include material that could be ethically posted in an explicitly public venue such as a journal or newspaper.

We acknowledge that patients may post their own medical information, obtained through secure health care portals or from traditional sources of clinical information; however, clinicians should not be held responsible for medical information posted to social media by patients or other parties.

\section{How Should Clinicians Maintain the Boundaries of the Patient-Clinician Relationship on Social Media?}

Patient-clinician interactions take place on multiple levels within online social networks. Overall, these interactions are more typically initiated by patients than by physicians or physicians in training. ${ }^{51}$ How does one maintain trust, empathy, and reliability if communication about a specific topic gradually moves on to become a "friend request" or a "follow" on social media? Here again, it is useful to begin with the traditional framework of professional norms and guidelines rooted in ethical principles. ${ }^{41}$ Personal relations may inhibit the collection of a detailed history, the completion of a rigorous physical examination, or the objective evaluation of clinical evidence, and thereby violate ethical principles of beneficence and nonmaleficence. Traditional norms of professional behavior suggest that clinicians refrain from treating close friends, family members, or romantic partners when other medical care is available. ${ }^{52}$ When personal relationships do develop between a patient and clinician, professional guidelines recommend that the professional relationship should end, and that the patient should be referred to the care of another clinician. Similarly, romantic relationships between patients and clinicians are considered unethical when they occur during the professional relationship, or when the clinician later "uses or exploits trust, knowledge, emotions, or influence derived from" a prior professional relationship. ${ }^{53}$

While these norms of ethical professional conduct can conceptually be applied directly to personal relationships involving social media, there is an added layer of complexity in 
How does the American Academy of Neurology address alerts and complaints about content on

social media? Social-media-related complaints pertaining to or against AAN members are addressed

like all other member complaints-i.e., in accordance with the AAN's Disciplinary Action Policy ${ }^{54}$

that it is sometimes difficult to define a personal relationship on social media. Terms like "friends" and "followers" are commonly used on social media, but often do not imply the same meaning of personal friendship inherent to parallel offline relationships. ${ }^{55}$ While some social media "friends" may be close friends with the same emotional intimacy as close friends in the offline world, many social media "friends" and "followers" are acquaintances or even strangers with no emotional involvement at all. Social media interactions may cross geographic and cultural boundaries, and social norms and definitions of relationships, including personal friendships, may vary. The environment and specific setting may also play a role; not befriending a patient in a small town where people generally know each other has a different implication than not doing so in a metropole where there might be more anonymity.

Because the recommendations against providing care to a close friend, family member, or romantic partner are based on the emotional content of the relationship, these recommendations then would not necessarily apply to social media "friends" or "followers." Social media "friendships" with patients are not prohibited, although a majority of physicians view online interactions with patients as ethically problematic due to confidentiality and pessimism about the actual quality of communication. ${ }^{51}$ If they do occur, clinicians are responsible for closely monitoring such relations for emotional developments, miscommunications, or unclear intentions that could undermine the professional relationship or cause harm to the patient. A specific challenge may arise when asked to provide medical advice on social media by followers or social media friends. Given that a social media relationship is not akin to a patient-doctor relationship, it is generally advised to refrain from offering individual medical advice on social media. ${ }^{56}$ This is also important from a legal perspective: health care professionals can expose themselves to lawsuits by providing medical advice via social media, especially in cases where there is no preexisting patient-provider relationship. ${ }^{39}$

Table 3 Examples of Do's and Don't's in Use of Social Media for Neurology Professionals

Do Don't

Apply the 4 principles of medical ethics and the American Academy of Neurology's Code of Professional Conduct when considering whether a specific social media post or interaction is ethical and professional

Post protected health information without the written consent of the patient involved

Utilize social media posts (including tweetorials) to educate patients and the public on matters of public health importance and to counteract misinformation

Provide individual medical advice over social media

Conduct proper fact checking and scientific vetting of information that you Post or repost false or misleading information

post or repost

Post research ideas and announcements to solicit feedback and discussion from professionals, affected communities, and other stakeholders

Engage in harassment or vitriolic attacks or post offensive or intimidating material from professional social media accounts

Consider potential limitations, such as selection bias, when using social media for research participant recruitment

Discriminate on the basis of categories such as race, ethnicity, socioeconomic status, age, gender, religion, national origin, or disability

Use social media to network with other health care professionals and Post sexually explicit material to professional social media accounts initiate clinical, research, and advocacy collaborations

Consider separation of personal and professional content online

Make posts or engage in social media relationships using professional social media accounts that violate the appropriate boundaries of the in-person patient-clinician relationship

Be aware of restrictions on social media use by relevant professional, licensing, and regulatory organizations, and that social media posts are Engage in social media use that distracts from or impairs your clinical care generally considered discoverable in legal matters

Be aware that data breaches on social media are common, unpredictable, and sometimes outside the control of both users and social media companies
Make posts on social media platforms-even ostensibly private posts-that you would not wish to be seen on the front page of national newspapers 
Table 4 Examples of How to Use Twitter and What Not to Do When Using Twitter ${ }^{57,58}$

\begin{tabular}{|c|c|}
\hline Do & Don't \\
\hline $\begin{array}{l}\text { Understand how to use Twitter for medical education using \#MedEd, } \\
\text { \#MedTwitter, \#NeuroTwitter Network, and \#EndNeurophobia }\end{array}$ & Post unverifiable medical facts without links to the evidence \\
\hline $\begin{array}{l}\text { Lurk on Twitter to understand the proper use of @, \#, reply, retweet, } \\
\text { share, and like }\end{array}$ & Post tweets without considering downstream effects \\
\hline Consider posting conflicts of interest in your Twitter bio & $\begin{array}{l}\text { Post about your book or other personal project without making your conflict of } \\
\text { interest clear }\end{array}$ \\
\hline $\begin{array}{l}\text { Consider participating in Twitter chats, especially in your } \\
\text { subspecialty }\end{array}$ & Extend beyond your subspecialty knowledge on specialty topics \\
\hline $\begin{array}{l}\text { Learn more about \#medtwitter teaching with \#medthread, } \\
\text { \#tweetorials, \#twearl, and \#postitipearl }\end{array}$ & Feel compelled to create unique content; you can just follow and learn from others \\
\hline Use \#hashtags carefully to allow others to find your content & \#use\#too\#many\#hashtags\#in\#your\#tweet \\
\hline $\begin{array}{l}\text { Share positive examples of social media for education and } \\
\text { professionalism }\end{array}$ & $\begin{array}{l}\text { Allow unprofessional behavior on social media to be unchallenged without } \\
\text { reaching out privately in a direct message (DM) to help others recognize the } \\
\text { consequences of their actions }\end{array}$ \\
\hline
\end{tabular}

\section{What Separates Clinicians' Private vs Professional Profiles?}

Posting of unprofessional content is common among clinicians and includes violations of privacy and confidentiality, as well as inappropriate language, sexually explicit material, and discriminatory statements. ${ }^{59}$ When using a social media account for professional purposes, such posts could be perceived offensive or intimidate potential patients, and undermine existing clinician-patient relationships. However, the definition of what constitutes "unprofessional" may not be univocally agreed upon, and may be influenced by biases towards race, gender, or other characteristics. This surfaced recently surrounding the publication of an article on unprofessional social media content among young vascular surgeons ${ }^{60}$ that was subsequently retracted.

Just as traditional norms of professional conduct, informed by the ethical principle of nonmaleficence, prohibit offensive or intimidating behavior towards patients in person, they also prohibit such behavior on social media where it will likely be encountered by patients or potential patients.

Statements can be taken out of context and rephrased in adversarial ways. For example, when pediatric neurologists elicited online commentary on vaccines or autoimmune diseases, ${ }^{61}$ the initiating posts were considered strictly professional, but the reactions to them became rapidly personal. Some digital attacks against physicians have been wellorchestrated, methodical, and intended to cause deliberate harm. ${ }^{61}$ Bound by physician-patient confidentiality, physicians may be unable to post replies in their defense.

Clinicians may encounter reputational challenges due to patient postings on their professional accounts or due to false ratings on social platforms. Practical advice provided by experts on cyberbullying is to refrain from answering publicly. Such situations may require a significant time investment to follow and monitor online postings and ratings and, if applicable, to attempt removal of false accusations or fake reviews. ${ }^{62}$ Monitoring one's online reputation ${ }^{63}$ is also important, even for those physicians not active on social media. In addition to patients and the general public, $70 \%$ of employers query social media sites prior to hiring. ${ }^{47}$

Professional Guidance Relating to Social Media Professional organizations should prioritize encouraging clinicians to adhere to norms for professional communication in their social media communications. Emerging evidence suggests that teaching online etiquette improves online professionalism as well. ${ }^{64}$ As social media has become more frequently utilized in health care, guidance for the bounds of acceptable and unacceptable behavior are available on increasing numbers of departmental, institutional, and professional society levels. ${ }^{42}$ For example, the code of conduct specific to use of the AAN web site puts forth the rules and guidelines shown in Table 2; similarly, the AAN has put forth rules and etiquette guidelines for the use of listservs (see AAN's Disciplinary Action Policy, reference provided in Figure 1). However, not all organizations have announced such guidance, and, if available, it is not always actively disseminated. An exemplary summary of do's and don't's in the use of social media for neurology professionals including guidance for use of Twitter as an example is provided in Tables 3 and 4. A case example of social media use with analysis is displayed in Figure 2.

\section{Discussion}

Increasing use of social media has expanded the availability and reach of medical information and social interactions, but it also carries important ethical obligations. Clinicians must adhere to core ethical principles and norms of professional behavior that have guided patient care for centuries, while updating and extending these principles to the novel domain 
Figure 2 Case Example of Social Media Use and Analysis of Ethical Principles Applied

\section{Case example of social media use and analysis of ethical principles applied:}

A neurologist posts, to elicit differential diagnostic ideas, in a closed social media group with onlyneurologists a case of a 36-year-old female with subacute ascending paresthesias and balance impairment. As pertinent part of the presentation, he adds in the post that the patient is employed by a chemical plant, and was exposed to certain chemicals for the past five years.

The post is read by a neurologist in the group who also is the sister of the manager of a large chemical plant. While not public knowledge, she is aware that there had been an investigation on a potential case of intoxication on an employee in the past. Alarmed, she passes on the information from the post to her brother, the manager, who indeed has an employee on medical leave for reasons he had not been aware of in detail.

\section{Case analysis and ethical principles involved:}

Posting a case to elicit a broader differential diagnosis: beneficence, justice; posting neurologist did not include direct identifiers, and posted in a closed group, and hence was under the impression that the principles of nonmaleficence and autonomy were maintained, while in fact this was not the case.

The reading neurologist is alarmed by the anonymous information that does, however, contain enough identifying information to create a context, and passes on the information that was posted. Driven by the principle of beneficence and justice, the principles of autonomy and nonmaleficence were not maintained here either.

of social media. Clinicians should challenge themselves to expand their traditional roles beyond the clinic or hospital setting and traditional ways of publishing. By using social media appropriately, clinicians can more broadly affect public health and medical literacy, an important service to provide at a time when information (and misinformation) is shared so extensively and rapidly. Timing and context of social media use affect how it is perceived; and yet, once something is publicized, it can be reposted, shared, or disseminated at any future time and in different contexts. ${ }^{35}$ As social media use grows, clinicians should aim to avoid moral pitfalls and public misrepresentation by aligning their professional social media communications with established norms of professional conduct. Interaction with social media has become a critical element in both individual and professional life, and current clinicians and trainees need to be educated in its use. Despite its many challenges, social media provides opportunities to greatly enhance our ability to improve the lives of our patients and to enrich our professional lives. The growing importance of social media in health care has accelerated dramatically during the COVID-19 pandemic $^{65}$ and is likely to continue for years to come.

\section{Acknowledgment}

The following individuals participated in the development of this position statement as members of the AAN Ethics, Law, and Humanities Committee: Winston Chiong, MD (UCSF Memory and Aging Center): critical review of manuscript; Robin Conwit, MD (National Institutes of Health): critical review of manuscript; Salvador CruzFlores, MD (Paul L. Foster School of Medicine, Texas Tech University Health Sciences Center): critical review of manuscript; Julie A. Kurek, MD (Augusta University at MCG): critical review of manuscript; Ariane Lewis, MD (NYU Langone Medical Center): critical review of manuscript; Barney J. Stern, MD (Johns Hopkins Outpatient Center): critical review of manuscript; Amy Tsou, MD (Emergency Care Research Institute): critical review of manuscript; Charles C. Flippen II, MD (UCLA Medical Department): critical review of manuscript; Ericka Greene (Simpson), MD (Methodist Hospital Houston): critical review of manuscript; William D. Graf, MD (Connecticut Children's Medical Center): critical review of manuscript; Sok Lee, MD (University of Pennsylvania Health System): critical review of manuscript. Richard J. Bonnie, LLB (Harrison Foundation Professor of Law and Medicine University of Virginia School of Law) participated in the development of this manuscript in his role as consultant to the Ethics, Law, and Humanities Committee by critical review of the manuscript. The authors thank Sarah Bird Nelson, JD (Associate Counsel, American Academy of Neurology) and John D. Hutchins, JD (General Counsel, American Academy of Neurology) for their critical review of the manuscript, feedback, and support.

\section{Study Funding}

The authors report no targeted funding.

\section{Disclosure}

The authors report no disclosures relevant to the manuscript. Go to Neurology.org/N for full disclosures.

\section{Publication History}

Received by Neurology April 1, 2021. Accepted in final form June 30, 2021. 
Appendix Authors

\begin{tabular}{lll}
\hline Name & Location & Contribution \\
\hline Katharina & University of Florida & Manuscript development, \\
M. Busl, MD, & drafting of original \\
MS & manuscript, review of data \\
& and relevant literature, \\
& critical revision of \\
& manuscript
\end{tabular}

Michael A. UT Southwestern Medical Rubin, MD Center

Manuscript development, drafting of original manuscript, review of data and relevant literature, critical revision of manuscript

Benjamin D. Yale University School of Manuscript development, Tolchin, MD Medicine drafting of origina manuscript, review of data and relevant literature, critical revision of manuscript

\begin{tabular}{ll}
\hline Dan & Inova Neuroscience and Spine \\
Larriviere, & Institute \\
MD, JD &
\end{tabular}

Manuscript development, review of data and relevant literature, critical revision of manuscript

Leon Ann \& Robert H. Lurie Manuscript development,

Epstein, MD Children's Hospital of Chicago review of data and relevant literature, critical revision of manuscript

\begin{tabular}{ll}
\hline Matthew & The Children's Hospital of \\
Kirschen, & Philadelphia \\
MD, PhD &
\end{tabular}

Manuscript development, review of data and relevant literature, critical revision of manuscript

Lynne P. University of Washington Manuscript development,

Taylor, MD Medical Center, Seattle Cancer Care Alliance

drafting of origina manuscript, review of data and relevant literature, critical revision of manuscript

\section{References}

1. American Academy of Neurology. Code of professional conduct [online]. aan.com/ globals/axon/assets/7708.pdf

2. Kohli MD, Daye D, Towbin AJ, Kotsenas AL, Heilbrun ME. Social media tools for department and practice communication and branding in the digital age. Radiographics. 2018;38(6):1773-1785.

3. Center PR. Social media fact sheet [online]. Accessed November 1. pewinternet.org/ fact-sheet/social-media/

4. Elkin N. How America Searches Health and Wellness. iCrossing; 2008.

5. Potts DC, Hohler AD. Neurologists and technology: the changing "Facebook" of practice. Neurol Clin Pract. 2013;3(2):149-154.

6. Chan TM, Stukus D, Leppink J, et al. Social media and the 21st-century scholar: how you can harness social media to amplify your career. J Am Coll Radiol. 2018;15(1 pt B):142-148.

7. Cabrera D, Roy D, Chisolm MS. Social media scholarship and alternative metrics for academic promotion and tenure. J Am Coll Radiol. 2018;15(1 pt B):135-141.

8. O'Reilly KB. 5 reasons why physicians should use social media professionally [online] Accessed November 5, 2020. ama-assn.org/practice-management/career-development/5-reasons-why-physicians-should-use-social-media

9. Avitzur O. Why we tweet: neurologists tell all. Neurol Today. 2019;42.

10. Ranginwala S, Towbin AJ. Use of social media in radiology education. J Am Coll Radiol. 2018;15(1 pt B):190-200.

11. Roland D, Spurr J, Cabrera D. Preliminary evidence for the emergence of a health care online community of practice: using a netnographic framework for Twitter hashtag analytics. J Med Internet Res. 2017;19(7):e252.

12. Witherspoon B, Braunlin K, Kumar AB. A secure, social media-based "case of the month" module in a neurocritical care unit. Am J Crit Care. 2016;25(4):310-317.

13. Nix JS, Gardner JM, Costa F, et al. Neuropathology education using social media. J Neuropathol Exp Neurol. 2018;77(6):454-460.

14. Sterling M, Leung P, Wright D, Bishop TF. The use of social media in graduate medical education: a systematic review. Acad Med. 2017;92(7):1043-1056.
15. Narayanaswami P, Gronseth G, Dubinsky R, et al. The impact of social media on dissemination and implementation of clinical practice guidelines: a longitudinal observational study. J Med Internet Res. 2015;17(8):e193.

16. Stephens SW, Williams C, Gray R, Kerby JD, Wang HE, Bosarge PL. Using social media for community consultation and public disclosure in exception from informed consent trials. J Trauma Acute Care Surg. 2016;80(6):1005-1009.

17. Gelinas L, Pierce R, Winkler S, Cohen IG, Lynch HF, Bierer BE. Using social media as a research recruitment tool: ethical issues and recommendations. Am J Bioeth. 2017; 17(3):3-14.

18. Johnson LA, Dias N, Clarkson G, Schreier AM. Social media as a recruitment method to reach a diverse sample of bereaved parents. Appl Nurs Res. 2019:151201.

19. Zhao M, Yang CC. Drug repositioning to accelerate drug development using social media data: computational study on Parkinson disease. J Med Internet Res. 2018; 20(10):e271.

20. Vosoughi S, Roy D, Aral S. The spread of true and false news online. Science. 2018; 359(6380):1146-1151.

21. Kim R, Park HY, Kim HJ, Kim A, Jang MH, Jeon B. Dry facts are not always inviting: a content analysis of Korean videos regarding Parkinson's disease on YouTube. J Clin Neurosci. 2017;46:167-170.

22. Meng Y, Elkaim L, Wang J, et al. Social media in epilepsy: a quantitative and qualitative analysis. Epilepsy Behav. 2017;71(pt A):79-84.

23. Sharma AE, Mann Z, Cherian R, Del Rosario JB, Yang J, Sarkar U. Recommendations from the Twitter hashtag \#DoctorsAreDickheads: qualitative analysis. J Med Internet Res. 2020;22(10):e17595

24. Mittal MK, Sloan JA, Rabinstein AA. Facebook: can it be a diagnostic tool for neurologists? BMJ Case Rep. 2012;2012:bcr2012006426.

25. Bove R. Social media in the age of the "new polio". N Engl J Med. 2019;380(13): 1195-1197.

26. Dhar VK, Kim Y, Graff JT, et al. Benefit of social media on patient engagement and satisfaction: results of a 9-month, qualitative pilot study using Facebook. Surgery. 2018;163(3):565-570.

27. Patel R, Chang T, Greysen SR, Chopra V. Social media use in chronic disease: a systematic review and novel taxonomy. Am J Med. 2015;128(12):1335-1350.

28. Feliciano JT, Salmi L, Blotner C, et al. Brain tumor discussions on Twitter (\#BTSM): social network analysis. J Med Internet Res. 2020;22(10):e22005.

29. World Medical Association. WMA Declaration of Geneva [online]. Accessed October 29, 2020. wma.net/policies-post/wma-declaration-of-geneva/

30. Strous RD, Karni T. Ethics of sharing medical knowledge with the community: is the physician responsible for medical outreach during a pandemic? J Med Ethics. 2020; 46(11):732-735.

31. Van Hees S, Siewe Fodjo JN, Wijtvliet V, et al. Access to healthcare and prevalence of anxiety and depression in persons with epilepsy during the COVID-19 pandemic: a multicountry online survey. Epilepsy Behav. 2020;112:107350.

32. Lai D, Wang D, Calvano J, Raja AS, He S. Addressing immediate public coronavirus (COVID-19) concerns through social media: utilizing Reddit's AMA as a framework for Public Engagement with Science. PLoS One. 2020;15(10):e0240326.

33. Kuss DJ, Griffiths MD. Social networking sites and addiction: ten lessons learned. Int J Environ Res Public Health. 2017;14(3):311.

34. Kind T. Professional guidelines for social media use: a starting point. AMA J Ethics. 2015;17(5):441-447.

35. Beauchamp TLC JF. Principles of Biomedical Ethics, 7th ed. Oxford University Press; 2012.

36. Higgs R. Truth-telling, lying and the doctor-patient relationship. In: Gillon R, ed. Principles of Health Care Ethics. John Wiley and Sons; 1994.

37. Kirklin D. Truth telling, autonomy and the role of metaphor. J Med Ethics. 2007; 33(1):11-14.

38. Buchanan T. Why do people spread false information online? The effects of message and viewer characteristics on self-reported likelihood of sharing social media disinformation. PLoS One. 2020;15(10):e0239666.

39. Ventola CL. Social media and health care professionals: benefits, risks, and best practices. $P$ T. 2014;39(7):491-520.

40. AMA. Professionalism in the use of social media [online]. Accessed December 18, 2019. ama-assn.org/delivering-care/ethics/professionalism-use-social-media

41. AMA. Code of medical ethics opinion 2.3.2 [online]. Accessed November 5, 2020. ama-assn.org/system/files/2019-06/code-of-medical-ethics-chapter-2.pdf

42. Farnan JM, Snyder Sulmasy L, Worster BK, et al. Online medical professionalism: patient and public relationships: policy statement from the American College of Physicians and the Federation of State Medical Boards. Ann Intern Med. 2013;158(8): 620-627.

43. George DR. Making "social" safer: are Facebook and other online networks becoming less hazardous for health professionals? J Clin Ethics. 2012;23(4):348-352.

44. Agarwal S. WhatsApp admits it could've handled data breach better. Economic Times. Epub 2019 Nov 21.

45. Isaac M, Frenkel S. Facebook security breach exposes accounts of 50 million users. The New York Times; Sep 28, 2018. Available at: nytimes.com/2018/09/28/technology/ facebook-hack-data-breach.html

46. Bosslet GT. Commentary: the good, the bad, and the ugly of social media. Acad Emerg Med. 2011;18(11):1221-1222.

47. Shore R, Halsey J, Shah K, et al. Report of the AMA council on ethical and judicial affairs: professionalism in the use of social media. J Clin Ethics. 2011;22(2):165-172.

48. Brynolf A, Johansson S, Appelgren E, Lynoe N, Edstedt Bonamy AK. Virtual colleagues, virtually colleagues: physicians' use of Twitter: a population-based observational study. BMJ Open. 2013;3. 
49. Ahmed W, Jagsi R, Gutheil TG, Katz MS. Public disclosure on social media of identifiable patient information by health professionals: content analysis of Twitter data. J Med Internet Res. 2020;22(9):e19746.

50. American Academy of Neurology. Code of conduct [online]. Accessed May 25, 2021 aan.com/AAN-Resources/Details/about-the-aan/code-of-conduct/

51. Bosslet GT, Torke AM, Hickman SE, Terry CL, Helft PR. The patient-doctor relationship and online social networks: results of a national survey. J Gen Intern Med. 2011;26(10):1168-1174.

52. Gold KJ, Goldman EB, Kamil LH, Walton S, Burdette TG, Moseley KL. No appointment necessary? Ethical challenges in treating friends and family. $N$ Engl J Med. 2014;371(13):1254-1258.

53. AMA. Code of medical ethics: self-treatment or treatment of immediate family members. AMA J Ethics. 2012;14:396-397.

54. American Academy of Neurology. Disciplinary action policy [online]. Accessed May 25, 2021. aan.com/siteassets/home-page/footer/membership-and-support/member-resources/professionalism-disciplinary-program/17fileacomplaint_ft.pdf

55. Lenhart A, Madden M. Friendship, strangers and safety in online social networks [online]. Accessed December 18, 2020. pewresearch.org/internet/2007/04/18/ friendship-strangers-and-safety-in-online-social-networks/

56. Nguyen BM, Lu E, Bhuyan N, Lin K, Sevilla M. Social media for doctors: taking professional and patient engagement to the next level. Fam Pract Manag. 2020;27(1):19-14.
57. Jaffe RC, O’Glasser AY, Brooks M, Chapman M, Breu AC, Wray CM. Your @attending will \#tweet you now: using Twitter in medical education. Acad Med. 2020; 95(10): 1618

58. O'Glasser AY, Jaffe RC, Brooks M. To tweet or not to tweet, that is the question Semin Nephrol. 2020;40(3):249-263.

59. Cooper CP, Gelb CA, Rim SH, Hawkins NA, Rodriguez JL, Polonec L. Physicians who use social media and other internet-based communication technologies. J Am Med Inform Assoc. 2012;19(6):960-964.

60. Hardouin S, Cheng TW, Mitchell EL, et al. RETRACTED: prevalence of unprofessional social media content among young vascular surgeons. J Vasc Surg. 2020;72(2):667-671.

61. Avitzur O. They've been cyberbullied. Neurol Today. 2019:2019.

62. Goldman E. How doctors should respond to negative online reviews. Forbes. 2013 Available at: forbes.com/sites/ericgoldman/2013/11/21/how-doctors-should-respond-to-negative-online-reviews/?sh=33bdfe53a0e 7

63. Beal A, Strauss J. Radically Transparent: Monitoring and Managing Reputations Online. Wiley Publishing; 2008.

64. Dimitri D, Gubert A, Miller AB, Thoma B, Chan T. A quantitative study on anonymity and professionalism within an online free open access medical education community. Cureus. 2016;8(9):e788.

65. Aggarwal NR, Alasnag M, Mamas MA. Social media in the era of COVID-19. Open Heart. 2020;7.

\section{Neurology $y^{\circledR}$ Online CME Program}

Earn CME while reading Neurology. This program is available only to online Neurology subscribers. Read the articles marked CME, go to Neurology.org, and click on CME. This will provide all of the information necessary to get started. The American Academy of Neurology (AAN) is accredited by the Accreditation Council for Continuing Medical Education (ACCME) to sponsor continuing medical education for physicians. Neurology is planned and produced in accordance with the ACCME Essentials. For more information, contact AAN Member Services at 800-879-1960.

\section{Visit the Neurology ${ }^{\circledast}$ Resident \& Fellow Website}

Click on Residents \& Fellows tab at Neurology.org.

Now offering:

- Neurology ${ }^{\circledR}$ Resident \& Fellow Editorial team information

- "Search by subcategory" option

- E-pearl of the Week

- RSS Feeds

- Direct links to Continuum ${ }^{\circledR}$, Career Planning, and AAN Resident \& Fellow pages

- Recently published Resident \& Fellow articles

- Podcast descriptions

- Blogs by Editors and Resident \& Fellow team members

f Find Neurology ${ }^{\circledR}$ Residents \& Fellows Section on Facebook: facebook.com/AANResidentsAndFellows

Follow Neurology ${ }^{\circledR}$ on Twitter: @GreenJournal \#NeurologyRF

(ㄱ) Find Neurology ${ }^{\circledR}$ Residents \& Fellows Section on Instagram: @aanbrain \#NeurologyRF 


\section{Neurology}

Use of Social Media in Health Care--Opportunities, Challenges, and Ethical
Considerations: A Position Statement of the American Academy of Neurology

Katharina M. Busl, Michael A. Rubin, Benjamin D. Tolchin, et al.

Neurology 2021;97;585-594

DOI 10.1212/WNL.0000000000012557

This information is current as of September 20, 2021

\section{Updated Information \&} Services

References

Citations

Subspecialty Collections

Permissions \& Licensing

Reprints including high resolution figures, can be found at: http://n.neurology.org/content/97/12/585.full

This article cites 44 articles, 6 of which you can access for free at: http://n.neurology.org/content/97/12/585.full\#ref-list-1

This article has been cited by 2 HighWire-hosted articles: http://n.neurology.org/content/97/12/585.full\#\#otherarticles

This article, along with others on similar topics, appears in the following collection(s):

All Education

http://n.neurology.org/cgi/collection/all_education

All Ethics in Neurology/Legal issues

http://n.neurology.org/cgi/collection/all_ethics_in_neurology_legal_iss ues

Professional conduct and ethics

http://n.neurology.org/cgi/collection/professional_conduct_and_ethics

Information about reproducing this article in parts (figures,tables) or in its entirety can be found online at:

http://www.neurology.org/about/about_the_journal\#permissions

Information about ordering reprints can be found online:

http://n.neurology.org/subscribers/advertise

Neurology ${ }^{\circledR}$ is the official journal of the American Academy of Neurology. Published continuously since 1951, it is now a weekly with 48 issues per year. Copyright @ 2021 American Academy of Neurology. All rights reserved. Print ISSN: 0028-3878. Online ISSN: 1526-632X.

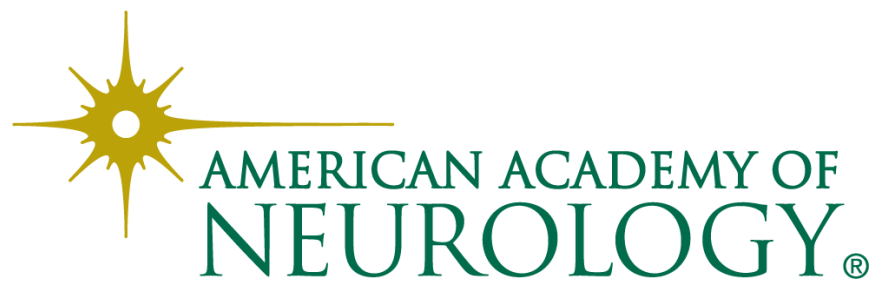

